\title{
Dynamic Simulation and Testing for Single-Equation Cointegrating and Stationary Autoregressive Distributed Lag Models
}

by Soren Jordan and Andrew Q. Philips

\begin{abstract}
While autoregressive distributed lag models allow for extremely flexible dynamics, interpreting the substantive significance of complex lag structures remains difficult. In this paper we discuss dynamac (dynamic autoregressive and cointegrating models), an $\mathrm{R}$ package designed to assist users in estimating, dynamically simulating, and plotting the results of a variety of autoregressive distributed lag models. It also contains a number of post-estimation diagnostics, including a test for cointegration for when researchers are estimating the error-correction variant of the autoregressive distributed lag model.
\end{abstract}

\section{Introduction}

Many important social processes vary systematically over time. Models designed to account for such dynamics have become more common in the social sciences. Applied examples range from prime ministerial approval (Clarke et al., 2000), to the determinants of prison admission rates (Jacobs and Helms, 1996), to preferences for different types of government spending (Wlezien, 1995), to how changing tax rates affect income (Mertens and Montiel Olea, 2018).

Dynamic processes take many forms. Some of these processes are integrated, such that the current value ("realization") of a series is an expression of all past values in the series plus some new innovation (i.e. $y_{t} \sim I(1)$ if $y_{t}=y_{t-1}+\epsilon_{t}$ ). These series are referred to as $I(1)$, non-stationary, or having a "unit root." ${ }^{1}$ Other processes revert back to some mean level over time. Since they are not integrated, often these series are termed stationary, or I(0). Stationary series are characterized by constant mean, variance, and covariance; non-stationary series violate one or more of these properties. An especially interesting relationship exists when two (or more) integrated variables are in a long-run relationship with each other, even if in the short term the series may move apart. Such series are said to be cointegrated. ${ }^{2}$

The job of properly modeling such a diverse set of dynamic processes is challenging. Researchers want to test whether a theoretical regressor of interest, $X$, has an effect on a dependent variable $y$, accounting for each series' own dynamics. Moreover, these effects might occur in both the short-run and long-run of the series. Additionally, in cases where we have multiple I(1) variables, we must test whether the variables are in a cointegrating relationship. Researchers still need a way to interpret the effects of these complex models. When modeling dynamics, then, we might be particularly drawn to a strategy that contributes to each of these goals.

We advocate for one particular specification because of its generalizability, flexibility and robustness to a variety of data-generating proceeses: autoregressive distributed lag (ARDL) models. ARDL models can account for multiple lags of independent variables, either in levels or in first-differences, as well as multiple lags of the dependent variable. Moreover, utilizing the ARDL-bounds testing procedure of Pesaran et al. (2001), we can test whether variables in the ARDL model are also in a cointegrating relationship. However, the very flexibility of this modeling strategy produces its own challenges. If the researcher includes multiple lags (or differences, or lagged differences) of some independent variable, it becomes increasingly difficult to discern various effects of a change in $X$ on $y$, beyond the individual coefficients estimated in the ARDL model. These are more complicated than static models (De Boef and Keele, 2008), since they often involve both short- and long-run effects of $X$ on $y .{ }^{3}$

We introduce a new R package, dynamac (Jordan and Philips, 2018), to help ameliorate these two challenges. The core of the package consists of two functions: pssbounds, which implements

\footnotetext{
${ }^{1} \mathrm{~A}$ unit-root is one common form of non-stationarity; a series could be non-stationary due to a linear trend, for instance.

${ }^{2}$ Stationary variables cannot be in cointegrating relationships, as their long-run response is to return to their mean value, not a linear combination of some other series.

${ }^{3}$ See Beck and Katz (2011) or Blackwell and Glynn (2018) for a discussion of this in the cross-sectional time series context.
} 
the ARDL-bounds testing procedure for cointegration (Pesaran et al., 2001), and dynardl, which estimates ARDL models and simulates the effect of some $X$ on $y$ by way of dynamic simulations. The simulations provided by the latter function help provide substantive inferences of some $X$ on $y$ (1) in both the short run and long run, (2) when $X$ appears in multiple forms (such as first-differences, lagged first-differences, and/or lagged levels), and (3) accounting for similar specifications of other control variables $Z$. We also include functions to easily take the lag, first-difference, and lagged-first difference of a series, as well as post-estimation diagnostics users can employ to ensure residuals from their resulting model are white noise. In doing so, we complement other R packages designed to show substantive and statistical significance of dynamic models (for instance, the dynsim package, Gandrud et al., 2015, 2016), as well as broader classes of models such as those compatible with Zelig (Choirat et al., 2018).

Below we explain the context of ARDL models generally, as well as cointegration testing and the ARDL-bounds test in particular. We then discuss dynamac functions to help estimate both the ARDLbounds test as well as the ARDL models (and their stochastic simulations). We provide illustrative examples of each function, and conclude by offering suggestions for future research.

\section{The general ARDL model}

The autoregressive distributed lag model has a very general form:

$$
\begin{aligned}
y_{t}, \Delta y_{t}= & \alpha_{0}+\delta T+\sum_{p=1}^{P} \phi_{p} y_{t-p}+\sum_{l_{1}=0}^{L_{1}} \theta_{1 l} x_{1, t-l_{1}}+\cdots+\sum_{l_{k}=0}^{L_{k}} \theta_{k l} x_{t-l_{k}}+ \\
& \sum_{m=1}^{M} \alpha_{m} \Delta y_{t-m}+\sum_{q_{1}=0}^{Q_{1}} \beta_{1 q_{1}} \Delta x_{1, t-q_{1}}+\cdots+\sum_{q_{k}=0}^{Q_{k}} \beta_{k q_{k}} \Delta x_{k, t-q_{k}}+\epsilon_{t}
\end{aligned}
$$

The left-hand side can be estimated either in levels $\left(y_{t}\right)$ or in first-differences $\left(\Delta y_{t}\right)$. This may be a function of a constant, a linear trend, up to $p$ lags of the dependent variable, a series of lags for each of the $k$ regressors-appearing either contemporaneously or with a lag- $m$ lagged first-differences of the dependent variable, and contemporaneous and/or lagged first-differences of each of the regressors. Lagged first-differences may enter into Equation 1 for theoretical reasons, or to help ensure that the resulting residuals $\epsilon$ are white noise. ${ }^{4}$ Since this model obviously results in a heavy parameterization, restrictions are often imposed. Two of the most common restrictions are the ARDL $(1,1)$ model with all-stationary data:

$$
y_{t}=\alpha_{0}+\phi_{1} y_{t-1}+\theta_{1,0} x_{1, t}+\cdots+\theta_{k, 0} x_{k, t}+\theta_{1,1} x_{1, t-1}+\cdots+\theta_{k, 1} x_{k, t-1}+\epsilon_{t}
$$

as well as its non-stationary and cointegrating variant, often referred to as an error-correction model: 5

$$
\Delta y_{t}=\alpha_{0}+\phi_{1} y_{t-1}+\theta_{1,1} x_{1, t-1}+\cdots+\theta_{k, 1} x_{k, t-1}+\beta_{1} \Delta x_{1, t}+\cdots+\beta_{k} \Delta x_{k, t}+\epsilon_{t}
$$

For clarity, lagged first-differences are not shown, although they may be added to Equations 2 and 3, either for theoretical reasons or to purge autocorrelation from the residuals. ${ }^{6}$

The strength and drawback of the ARDL model should be immediately apparent: while researchers can specify a variety of lagged levels and differences to account for theory as well as ensure whitenoise (random) residuals (that is, no residual autocorrelation), the same flexibility can make inferences regarding the total effect of any individual $X$ variable difficult to discern. This is exacerbated even more when we consider that these variables might have short-run and long-run effects. In other words, an immediate change in an $X$ variable might have an immediate impact in the contemporaneous period $t$, but if lagged values of $X$ also appear in the model, this effect will persist for multiple time periods. Moreover, if the dependent variable is entered into the model in lagged levels through $\phi_{p}$, the effects of the independent variable $X$ in some time period $t$ persist over time. There is a cumulative-or long-run-effect across time, given a change in $X$ in a single time period. In simple cases this can be calculated as a non-linear combination of the lagged parameter estimate and the parameter on the lagged dependent variable (De Boef and Keele, 2008). Yet even these calculations become tedious with multiple lags of the regressors and the dependent variable.

We circumvent this difficulty by employing stochastic simulations rather than direct interpretation of coefficients in order to show statistical and substantive significance. Dynamic stochastic simulations

\footnotetext{
${ }^{4}$ i.e., $\epsilon \sim N\left(0, \sigma^{2}\right)$. We discuss the importance of white-noise residuals below.

${ }^{5}$ Of course, all-stationary series may be estimated in an error-correction model as well (De Boef and Keele, 2008).

${ }^{6}$ i.e., users could add: $\sum_{m=1}^{M} \alpha_{m} \Delta y_{t-m}+\sum_{q_{1}=0}^{Q_{1}} \beta_{1 q_{1}} \Delta x_{1, t-q_{1}}+\cdots+\sum_{q_{k}=0}^{Q_{k}} \beta_{k q_{k}} \Delta x_{k, t-q_{k}}$.
} 
provide an alternative to direct hypothesis testing of coefficients, instead focusing on simulating meaningful counterfactuals from model coefficients many times and drawing inferences from the central tendencies of the simulations. Such simulations are becoming increasingly popular with increased computing power, as demonstrated in the social sciences by recent methodological and applied work (Tomz et al., 2003; Breunig and Busemeyer, 2012; Williams and Whitten, 2012; Philips et al., 2015, 2016; Gandrud et al., 2015; Choirat et al., 2018).

Recall that the other challenge we wish to confront is that of identifying cointegration in autoregressive distributed lag models in error-correction form. In instances of small-sample data, especially of time points $t$ of 80 or less, traditional tests like the Engle-Granger "two-step" method (Engle and Granger, 1987) or the Johansen $(1991,1995)$ approaches too often conclude cointegration when it does not exist (Philips, 2018). An alternative test, proposed by Pesaran et al. (2001), is more conservative, meaning it does not conclude cointegration when it does not exist, especially in small samples. This test, which we call the ARDL-bounds test, is desirable for the social sciences, where shorter time series (smaller samples) are quite common. The difficulty of the ARDL-bounds test is that it requires a specific form of the ARDL model and unique critical values. While these are not insurmountable obstacles, the usefulness of the test would be extended if software existed to get and test these critical values for the user.

In dynamac, these challenges are resolved through pssbounds (named for Pesaran, Shin and Smith, the authors of the test), which implements the ARDL-bounds test for cointegration, and dynardl, which estimates autoregressive distributed lag models and implements the stochastic simulations we describe above. The commands also have the virtue of working together: estimating an ARDL model in error-correction form with dynardl by nature stores the values necessary to execute the ARDL-bounds test with pssbounds. Below, we use a substantive example to motivate our discussion of the package in greater detail.

\section{Modeling using dynamac}

We illustrate the process-autoregressive distributed lag modeling, testing for cointegration with pssbounds, and interpretation of $X$ through stochastic simulations-using data originally from Wright (2017) on public concern about inequality in the United States. ${ }^{7}$ For our example, assume that public concern about inequality in the US, Concern (concern), is a function of the share of income going to the top ten percent, Income Top 10 (incshare10). We also hypothesize that the unemployment rate, Unemployment (urate), affects concern over the short-run (i.e., is not cointegrating):

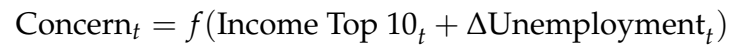

Before estimating any model using dynamac, users should first check for stationarity. A variety of unit root tests can be performed using the urca package (Pfaff et al., 2016). These suggest that all three series are integrated of order I(1), as they appear integrated in levels but stationary in first-differences $(\Delta)$, shown in Table 1 .

Table 1: Unit root tests

\begin{tabular}{lcccc} 
& Augmented DF & Phillips-Perron & Dickey-Fuller GLS & KPSS \\
\hline Concern & 0.688 & $-3.437^{*}$ & -0.893 & $0.642^{*}$ \\
$\Delta$ Concern & $-3.507^{*}$ & $-7.675^{*}$ & $-3.124^{*}$ & $0.814^{*}$ \\
Unemployment & -0.612 & -2.762 & $-2.802^{*}$ & 0.224 \\
$\Delta$ Unemployment & $-5.362^{*}$ & $-4.879^{*}$ & $-5.308^{*}$ & 0.064 \\
Income Top 10 & 2.992 & 0.442 & 0.994 & $2.482^{*}$ \\
$\Delta$ Income Top 10 & $-3.170^{*}$ & $-6.244^{*}$ & $-4.032^{*}$ & 0.218 \\
\hline
\end{tabular}

One augmenting lag included for all tests. $*: p<0.05$. Augmented Dickey-Fuller, PP, and DF-GLS have null hypothesis of a unit-root, while KPSS has a null of stationarity.

Given that all series appear to be I(1), we proceed with estimating a model in dynardl in errorcorrection form, and then testing for cointegration between concern about inequality and the share

\footnotetext{
${ }^{7}$ Available at: http:/ / dx.doi.org/10.7910/DVN/UYUU9G. For simplicity, we use a smaller version of Wright's dataset with missing values at the beginning of the series removed.
} 
of income of the top 10 percent. In general, we suggest using this strategy-outlined in Philips (2018) - along with alternative tests for cointegration. ${ }^{8}$ Our error-correction model appears as:

$$
\begin{aligned}
& \Delta \text { Concern }_{t}=\alpha_{0}+\phi_{1} \text { Concern }_{t-1}+\theta_{1}{\text { Income Top } 10_{t-1}+}^{+}
\end{aligned}
$$

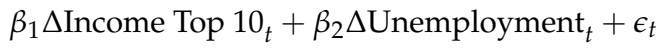

where we assume $\epsilon_{t} \sim N\left(0, \sigma^{2}\right)$. Now we estimate this model with dynardl.

\section{Estimation using dynardl}

The syntax for dynardl, the main function in the package, is as follows:

- formula, a formula of the type $y \sim x_{1}+x_{2}+x_{3}+\ldots x_{k}$. Note the variables do not need to be lagged or differenced in the specification; these transformations will be handled automatically by dynardl.

- data, an optional argument specifying a particular dataset in which the variables from formula can be found.

- lags, a list of variables to be lagged and their corresponding lagged levels. For instance, if an analyst had two variables, $X_{1}$ and $X_{2}$, that he or she wished to incorporate with a single lag at $t-1$, he or she would specify lags $=\operatorname{list}(" \mathrm{X} 1 "=1, " \mathrm{X} 2 "=1)$. If he or she wanted to incorporate multiple lags on $X_{2}$ from time periods $t-1$ and $t-2$, the code would appear as lags = list ("X1" = 1, "X2" = $c(1,2, \ldots)$, expanded for however many lags were desired.

- diffs, a vector of variables to be differenced, i.e., included as $\Delta X_{t}$. Only first-differences are supported. For instance, if an analyst wanted to first-difference $X_{1}$ and $X_{3}$, he or she would include diffs $=c(" X 1 ", X 3 ")$.

- lagdiffs, a list of variables to be included with lagged first-differences. The syntax is identical to lags, but instead of incorporating lagged levels of the relevant variable $X_{k}$ at $t-1$, lagged differences $\Delta X_{k, t-1}$ are included. For instance, if the analyst wanted to include a first lagged difference of $X_{1, t}$ at $t-1$, he or she would include lagdiffs = list ("X1" = 1).

- levels, a vector of variables to be included in levels contemporaneously-i.e., at time $t$. If the analyst wanted to include $X_{2}$ and $X_{3}$ in levels at time $t$, he or she would include levels $=$ c("X2", "X3").

- ec, a TRUE/FALSE option for whether the model should be estimated in error-correcting form. If ec = TRUE, the dependent variable will be run in differences. The default is FALSE.

- trend, a TRUE/FALSE option for whether a linear trend should be included in the regression. The default is FALSE.

- constant, a TRUE/FALSE option for whether a constant should be included in the regression. The default is TRUE.

- modelout, a TRUE/FALSE option for whether model output from the ARDL model should be printed in the console. The default is FALSE.

- simulate, a TRUE/FALSE option for whether any shocks should be simulated. Since simulations are potentially computationally intensive, if the analyst is simply using dynardl to test for cointegration using the bounds procedure, or wishes to just view the model output, he or she might not wish to estimate simulations in the interim. The default is FALSE. ${ }^{9}$

Reading the above, dynardl is simply an engine for regression, but one that allows users to focus on theoretical specification rather than technical coding. All variables in the model are entered into the formula. In this sense, dynardl can be used in any ARDL context, not just ones in which the user is also expecting cointegration testing or dynamic simulations.We estimate our example model shown in Equation 5 using dynardl as follows:

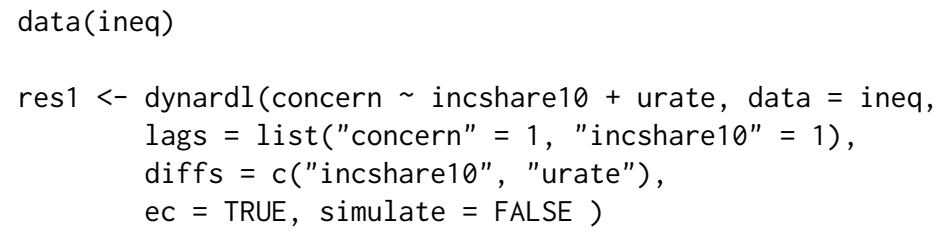

${ }^{8}$ These include the Johansen (1995) cointegration test (available in urca) or the proposed test by Engle and Granger (1987), among others.

${ }^{9}$ For this first example, we will treat this option as FALSE. 
[1] "Error correction (EC) specified; dependent variable to be run in differences."

We specify the formula by letting dynardl know what the dependent variable and the regressors are. Next, in the lags option, we let the program know we want a lag at $t-1$ for the dependent variable and for Income Top $10 .{ }^{10}$ Since Unemployment did not appear in lag form in Equation 5, it does not appear in lags. In diffs, we let dynardl know to include the first-difference for both Income Top 10 and Unemployment. The option ec = TRUE estimates the dependent variable in error-correction form (i.e., takes the first-difference of Concern), and the program will issue a message indicating to the user that such a transformation has taken place. ${ }^{11}$ By setting simulate $=$ FALSE, we save on computing time by estimating the model without performing stochastic simulations needed to make substantive inferences through stochastic simulations, as shown in the next sections. This is useful if the residuals of our first model indicate residual autocorrelation and require respecification.

Presenting the model summary is the usual summary (foo):

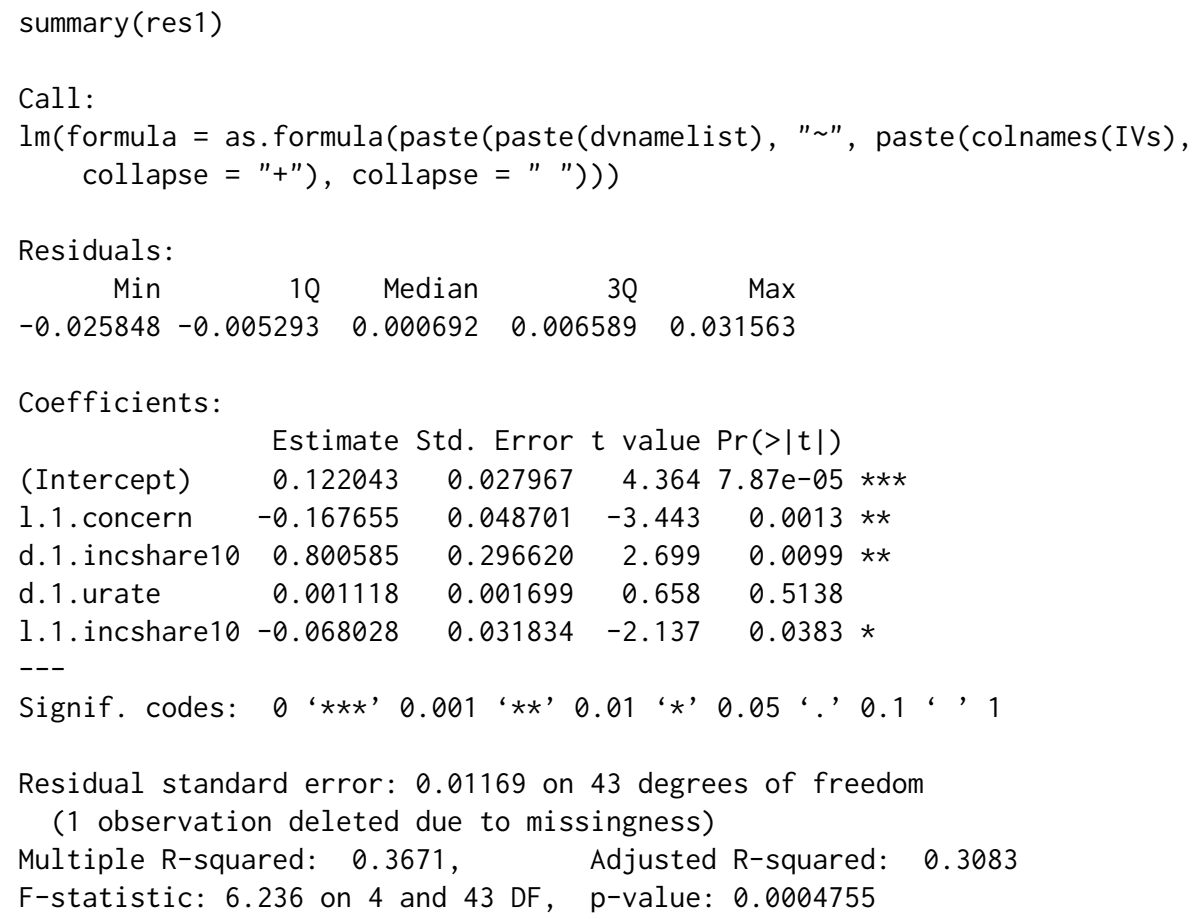

As shown from the regression results, dynardl has included a constant, the lagged dependent variable, 1.1. concern, the first difference of the two regressors (Income Top 10 and Unemployment), as well as the lag of Income Top $10 .{ }^{12}$ While changes in Income Top 10 affect changes in Concern in the short-run, changes in Unemployment do not have a statistically significant effect in the short-run. The lag of Income Top 10 is negative and statistically significant. Moreover, the parameter on the lagged dependent variable is negative, between 0 and -1 , and statistically significant, giving us cursory evidence of a cointegrating process taking place; we use a statistical test for this below.

\section{Post-estimation diagnostics}

An essential component of ARDL modeling is ensuring that the residuals from any ARDL estimation are white noise. One symptom of residual autocorrelation in the presence of a lagged dependent variable (where $\phi_{1} \neq 0$ ) is that OLS will result in biased and inconsistent estimates (c.f., Keele and Kelly, 2006, pp. 189-191). Autocorrelation is especially pernicious when using the ARDL-bounds cointegration test, since the test relies on the assumption of, "serially uncorrelated errors for the validity of the bounds tests" (Pesaran et al., 2001, p. 311). Moreover, a number of scholars stress that

\footnotetext{
${ }^{10}$ If we wanted further lags, we could specify it here, for instance lags = list $("$ concern" $=c(1,2)$, "incshare $10 "=2$, "urate" $=2$ ) would add lags at $t-1$ and $t-2$ for concern, and at $t-2$ for incshare 10 and urate.

${ }^{11}$ Setting this option to 'FALSE' would estimate the dependent variable in levels. If ec = TRUE, the saved object will also contain \$pssbounds, described below.

${ }^{12}$ Lagged variables are denoted by $1 . X$.variable, where $X$ is the lag. First-differences are denoted by d.variable. Lagged first-differences are denoted by 1. d.X.variable, where $X$ is the lag.
} 
autocorrelation is likely indicative of model misspecification more broadly-which may cause omitted variable bias in addition to incorrect standard errors-and thus testing for autocorrelation can help inform users as to which covariates should be included or excluded, as well as the correct dynamic specification (Mizon, 1995; Keele and Kelly, 2006).

To assist users in model selection and residual testing, we offer dynardl . auto.correlated. This function takes the residuals from an ARDL model estimated by dynardl and conducts two tests for autocorrelation-the Shaprio-Wilk test for normality and the Breusch-Godfrey test for higher-order serial correlation-as well as calculates the fit statistics for the Akaike information criterion (AIC), Bayesian information criterion (BIC), and log-likelihood. The arguments for this function are:

- $x$, a dynardl model object.

- bg. type, a character string, either "Chisq" or "F" of the type of Breusch-Godfrey test for higherorder serial correlation. This returns either the Chi-squared test statistic or the F statistic. The default is "Chisq".

- digits, an integer for the number of digits to round fit statistics to (by default, this is three digits).

- order, an integer for the highest possible order of autocorrelation to test in the data. By default, this is computed by the length of the series.

- object. out, a TRUE/FALSE option for whether to print this output into an object. This might be useful if the analyst is comparing multiple ARDL objects and testing for white-noise residuals on the basis of fit criteria like AIC. In this case, the analyst could assign the output to some object for later comparison.

To run this post-estimation diagnostics for our model above, we type:

dynardl.auto.correlated(res1)

Breusch-Godfrey LM Test

Test statistic: 3.704

p-value: 0.054

H_0: no autocorrelation up to AR 1

Shapiro-Wilk Test for Normality

Test statistic: 0.965

p-value: 0.158

H_0: residuals are distributed normal

Log-likelihood: 148.094

AIC: -284.187

BIC: -272.96

Note: AIC and BIC calculated with $\mathrm{k}=5$ on $\mathrm{T}=48$ observations.

Breusch-Godfrey test indicates we reject the null hypothesis of no autocorrelation at $\mathrm{p}<0.10$.

Add lags to remove autocorrelation before running dynardl simulations.

Given the results of the Breusch-Godfrey LM test for autocorrelation, there appears to be some autocorrelation still in the residuals. To mitigate this, we can add lagged first-differences to our model (Philips, 2018). For instance, to add a lagged first-difference of the dependent variable:

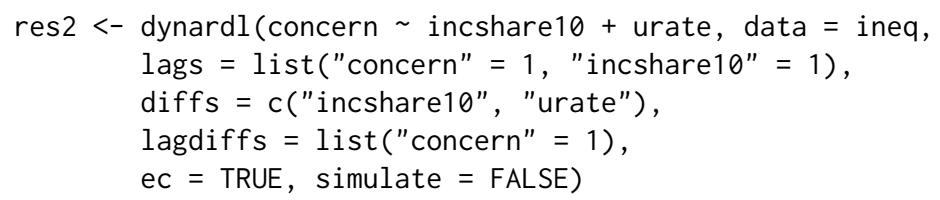

For brevity the results are not shown here, but they indicate that $\mathrm{AR}(1)$ autocorrelation is no longer present in the residuals after adding a lagged first-difference of the dependent variable. 


\section{Cointegration testing using pssbounds}

Recall the definition of cointegration: two or more integrated series of order I(1) are cointegrated if some linear combination of them results in a stationary series. ${ }^{13}$ This means that they have some long-run relationship; although temporary shocks may move the series apart, there is an attracting force that brings them back into a stable equilibrium relationship over the long-run. These movements are commonly referred to as being "corrected" or "re-equilibrated"; cointegrated series do not simply happen to move together, but are quite literally brought back into long-run relationship by an attracting force. Since not all I(1) series are cointegrating, failing to account for cointegration-in other words, including I(1) series in an error-correction model when they are not cointegrating-can lead to a drastic increase in Type I error (c.f., Grant and Lebo, 2016).

A variety of cointegration tests have been proposed, which we do not discuss here. Instead, we advocate for a test that has been shown to demonstrate strong small sample properties (Philips, 2018); the ARDL-bounds test for cointegration (Pesaran et al., 2001). The ARDL-bounds procedure proceeds as follows. First, analysts must ensure that the regressors are not of order I(2) or more, and that any seasonal component of the series has been removed. Second, analysts must ensure that the dependent variable $y$ is I(1). A wide variety of unit root tests are designed to assist in this, including the Dickey-Fuller, Elliott-Rothenberg-Stock, Phillips-Perron, and Kwiatkowski-Phillips-Schmidt-Shin tests. We reference these tests in Table 1.

Once the analyst ensures that the dependent variable $y$ is I(1), and the independent variables are not of order I(2) and contain no seasonal components, he or she estimates an ARDL model in error-correction form. ${ }^{14}$ That form resembles Equation 6, where the dependent variable is run in differences:

$$
\begin{aligned}
\Delta y_{t}= & \alpha_{0}+\phi_{1} y_{t-1}+\theta_{1,1} x_{1, t-1}+\cdots+\theta_{k, 1} x_{k, t-1}+\beta_{1} \Delta x_{1, t}+\cdots+\beta_{k} \Delta x_{k, t}+ \\
& \sum_{m=1}^{M} \alpha_{m} \Delta y_{t-m}+\sum_{q_{1}=1}^{Q_{1}} \beta_{1 q_{1}} \Delta x_{1, t-q_{1}}+\cdots+\sum_{q_{k}=1}^{Q_{k}} \beta_{k q_{k}} \Delta x_{k, t-q_{k}}+\epsilon_{t}
\end{aligned}
$$

Two points are key. First, any independent variables that are potentially I(1) must be entered in lagged levels at $t-1$. Second, the resulting residuals of the ARDL model must be white noise in order to perform the cointegration test (approximately normally distributed, with no residual autocorrelation). If they are not, the analyst should incorporate additional lags of the first difference of the variables until they are (Philips, 2018). A variety of tests exist to help determine whether the residuals are white noise, as well as aiding in model specification, including information criteria (like SBIC and AIC), Breusch-Godfrey tests, Durbin's Alternative test, and Cook-Weisberg. Users can find most of these in dynardl. auto. correlated, discussed in the previous section.

The special case of the ARDL model in Equation 6 is that the $X$ variables appearing in levels $\left(\theta_{1} \ldots \theta_{k}\right)$ are the only ones that can possibly be in a cointegrating relationship with the dependent variable $y$. The ARDL-bounds test for cointegration works by using a Wald or F-test on the following restriction from Equation 6:

$$
H_{0}: \phi_{1}=\theta_{1,1}=\cdots=\theta_{k, 1}=0
$$

In other words, that the coefficients on variables appearing in first lags are jointly equal to zero. The null hypothesis is that of no cointegration. Rejecting the null hypothesis indicates there is a cointegrating relationship between the series. In addition to the F-test, a one-sided t-test may be used to test the null hypothesis that the coefficient on the lagged dependent variable (in levels) is equal to zero, or:

$$
H_{0}: \phi_{1}=0
$$

The alternative to this test is that $\phi_{1}<0$, or that $y$ is cointegrating with the regressors. This is known as the bounds t-test.

The procedure and tests themselves are relatively straightforward to implement, but are complicated by two factors. The first is that critical values for these tests are non-standard, meaning that they are not readily testable in canned procedures. The correct (asymptotic) critical values are

\footnotetext{
${ }^{13}$ For instance, given $y_{t}=\kappa_{0}+\kappa_{1} x_{t}+z_{t}$, cointegration would exist if $z_{t} \sim \mathrm{I}(0)$. Higher orders of cointegration may also be cointegrating - something known as multicointegration-but these are not supported by the ARDL-bounds test.

${ }^{14}$ Note this does not require the analyst to make the sharp distinction between an $\mathrm{I}(0)$ or an $\mathrm{I}(1)$ regressor, a special benefit of the ARDL-bounds procedure. This is especially useful when "near integrated" series can appear to be integrated in small samples even though, if we were to observe more innovations, the series would ultimately return to some mean value (that is, it would be stationary).
} 
provided by Pesaran et al. (2001), and the small sample critical values for the F-statistic are given by Narayan (2005). ${ }^{15}$ Moreover, the appropriate critical values depend on the "case" of the regression: a combination of whether the regression includes a (restricted) trend term (or not) and a (restricted) constant (or not). As Philips (2018) describes, whether the resulting F-statistic is higher than the I(1) critical value, below the $I(0)$ critical value, or between the two, gives differential evidence on the integrated nature of the $X$ variables and the potential cointegrating relationship between them.

Just looking at the above discussion: even if the test is powerful, it can be difficult to implement and interpret correctly. Accordingly, we offer two functions to help implement the test and get dynamic inferences. The first function, dynardl, estimates the ARDL relationship described above (to obtain the resulting F-statistic and t-statistic). The second function, pssbounds, takes the results of the ARDL model and implements the ARDL-bounds test for cointegration, providing the user with the correct critical values and an easy-to-understand description of hypothesis testing.

To summarize, if we find that the dependent variable and regressors are all I(1), they can only appear in lagged levels in the error-correction model if there is evidence of cointegration. dynamac contains the Pesaran et al. (2001) ARDL-bounds cointegration test to assist users in testing for this. To implement the bounds testing procedure, we introduce the function pssbounds. This function has the following syntax:

- data, an optional argument expecting a dynardl model, which calculates the following arguments for the user. If none is given, the user must supply each of the following:

- obs, an integer for the number of observations in the model time series.

- fstat, the $F$ statistic on the restriction that each of the first lags in the model (including the lagged dependent variable) are jointly equal to zero.

- tstat, the $t$ statistic on the lagged dependent variable in the error-correction model.

- case, a numeric 1-2-3-4-5 or numeral I-II-III-IV-V of the case of the regression.

- 1: No intercept and no trend

- 2: Restricted intercept and no trend

- 3: Unrestricted intercept and no trend (the most common case)

- 4: Unrestricted intercept and restricted trend

- 5: Unrestricted intercept and unrestricted trend

- $k$, the number of regressors appearing in first lags.

- digits, an integer for the number of digits to round fit statistics to (by default, this is three digits).

- object. out, a TRUE/FALSE option for whether to print this output into an object. The default is FALSE.

This command can be implemented in two ways. First, users can run the appropriate model (following the instructions of Philips (2018)) and pass the relevant arguments-obs, fstat, tstat, case, and k-to pssbounds. Alternatively - and as we advocate-users can estimate the model using foo <-dynardl (...) and then, post-estimation, run pssbounds (foo). ${ }^{16}$

Moving back to our example, to test for cointegration, we use the pssbounds command: ${ }^{17}$

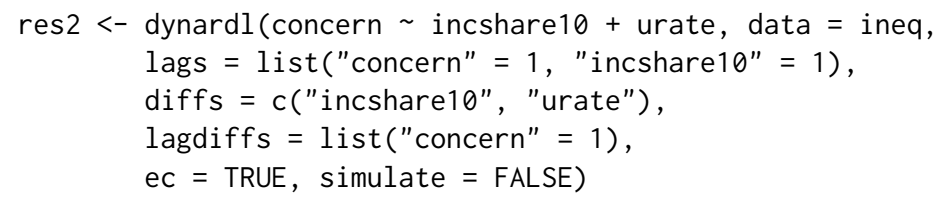

\footnotetext{
${ }^{15}$ No small-sample critical values are given for the t-test, so it should not be used to conclusively decide whether a cointegrating relationship exists; rather, only for confirmatory evidence.

${ }^{16}$ As described earlier, this only applies to models where ec = TRUE, as only error-correcting models can potentially be cointegrating.

${ }^{17}$ To re-emphasize, this test is inappropriate if the residuals are not white-noise (Pesaran et al., 2001, p. 311). Therefore, it is crucial to users to first test for stationarity, run dynardl, and adjust their model as needed before testing for cointegration.
} 
Number of Regressors (k): 1

Case: 3

$\begin{array}{lll} & \text { F-test } & - \\ \text { 10\% critical value } & 4.19 & 4.94 \\ \text { 5\% critical value } & 5.22 & 6.07 \\ 1 \% \text { critical value } & 7.56 & 8.685\end{array}$

\begin{tabular}{|c|c|c|}
\hline- & t-test & \\
\hline \multicolumn{3}{|c|}{$<----I(0)---\infty-1(1)$} \\
\hline $10 \%$ critical value & -2.57 & -2.91 \\
\hline $5 \%$ critical value & -2.86 & -3.22 \\
\hline $1 \%$ critical value & -3.43 & -3.82 \\
\hline$t$ statistic $=-3.68$ & & \\
\hline
\end{tabular}

t-statistic note: Small-sample critical values not provided for Case III. Asymptotic critical values used.

The program displays the number of observations from the regression, the number of regressors appearing in lagged levels (i.e., the cointegrating equation), and the case (unrestricted intercept and no trend); all of these are necessary to obtain the special critical values used by Pesaran et al. (2001). ${ }^{18}$ This situates the F-statistic and t-statistic with the correct critical values for the appropriate test. Users are then free to compare the test statistics to the critical values and make the appropriate deduction regarding cointegration in the sample model.

In our example, since the value of the F-statistic exceeds the critical value at the upper I(1) bound of the test at the $1 \%$ level, we may conclude that Income Top 10 and Concern about inequality are in a cointegrating relationship. As an auxiliary test, pssbounds displays a one-sided test on the $t$-statistic on the lagged dependent variable. ${ }^{19}$ Since the t-statistic of -3.684 falls below the $5 \%$ critical value I(1) threshold, this lends further support for cointegration. Taken together, these findings indicate that there is a cointegrating relationship between concern about inequality and the income share of the top 10 percent, and that Equation 6 is appropriately specified. ${ }^{20}$

\section{Gaining substantive and statistical significance of results using dynardl}

Once users have decided on the appropriate theoretical model-accounting for the appropriate lags of the independent variables, first-differenced variables, and so on-and drawn conclusions regarding cointegration using pssbounds (if applicable), their resulting models might be somewhat complicated. Our solution to inferences in the face of this complexity is the use of stochastic simulations. ${ }^{21}$

If a user runs dynardl with the argument simulate = TRUE, then the following options become available:

- shockvar, the independent variable to be shocked in the simulation. This is the independent variable for which we want to estimate an effect. Analysis should enter this in quotes, like shockvar $=$ "X1". This is the only option required without a default: we must know which variable we want inferences about.

\footnotetext{
${ }^{18}$ Pesaran et al. (2001) provide asymptotic critical values. We use small-sample critical values, calculated by Narayan (2005), when available.

${ }^{19}$ We call this an auxiliary test since only asymptotic critical values are available, while small sample critical values are available for most F-tests. When not available, pssbounds issues a warning note.

${ }^{20} \mathrm{Had}$ we not found evidence of cointegration, (either the F-statistic fell between or below the I(1) and I( 0$)$ critical values), we could adjust our model accordingly, as outlined by Philips (2018).

${ }^{21}$ If users are aiming for analysis to be able to be repeated, they should set a seed before engaging in stochastic simulations.
} 
- shockval, the amount by which the independent variable should be shocked. The default is a standard deviation of the shock variable.

- time, the time period within the range of the simulation when to shock the independent variable of interest (the shockvar). The default is 10.

- qoi, whether we should summarize the response of the dependent variable with the mean or the median. Although the default is mean, if there is underlying skew in the distribution, it might be better summarized by median (Rainey, 2017).

- forceset, a list of variables and their values that should be set to particular values during the simulations. By default, variables in levels are held at their means, and variables in differences are held at 0 . If forceset is not specified, the simulation will be estimated using these default values. However, if the analyst wanted to investigate the change in $y$ when some variables are at different values, he or she should do this with forceset. These values can be any user-defined value, including means, medians, percentiles, or other values of interest. For instance, if $X_{1}$ was meant to be held at 3 (rather than the mean of $X_{1}$ ), the analyst would specify forceset $=$ list ("X1" = 3).

- range, an integer for how long the simulation is to run (the default is 20 periods)

- burnin, the number of time periods before the range begins. burnin allows time for the variables to equilibriate. The default is 20 . This means that 20 time periods are simulated, then the range of the simulation begins. Users are not shown the burnin time periods.

- sims, the number of simulations to run. The quantities of interest are created from these simulations. The default number is 1000 .

- sig, an integer for any user-desired significance level in the form of $1-p$. So if the user wants a $p$ value of 0.10 , sig would be 90 . The default level is 95 .

- expectedval, a TRUE/FALSE option for whether the expected values (which average errors within simulations) or predicted values (which do not) are desired. Unless the analyst has a strong reason to use expected values, we recommend using predicted values by including expectedval $=$ FALSE, the default.

dynardl takes this set of arguments and generates the appropriate autoregressive distributed lag given the levels, lagged levels, first-differences, and lagged first-differences of the variables provided. Once this model is estimated using OLS, dynardl simulates the quantities of interest. Specifically, the coefficients $\hat{\beta}$ are simulated as draws (with number of sims) from a multivariate normal distribution with mean of $\hat{\beta}$ and variance from the variance-covariance of the estimated model (using the MASS package from Ripley (2018)). We introduce uncertainty into these simulations by simulating $\hat{\sigma}^{2}$ scaled by random draws from the chi-squared distribution. We then use this estimate of $\hat{\sigma}^{2}$ to add back in fundamental random error to the predicted value of each simulation. These predictions come from set levels of the independent variables: the $X$ variables in levels are held at their means and other variables in differences are held at 0 . Users can override this default by specifying a different value for any variable using forceset. Note that the equation is given time to equilibriate (through the use of burnin periods) before the independent variable is shocked.

Perhaps the most important argument is shockvar. This is the variable for which the user wants some sort of inference regarding the effect of an independent variable on the dependent variable: the response in the dependent variable is created by shocking the shockvar. At time time, the shockvar is "shocked" by the amount of shockval. This shock is distributed appropriately, as defined by the model specified. For instance, if the shockvar is entered into the model in lagged levels at time $t-1$, that $X$ variable would be shocked at time +1 . Just like in an interactive model, one of the best ways to gain inferences regarding the effect of $X$ on $y$ is by varying a single $X$ at a single point in time. Accordingly, only a single shockvar can be specified.

The only thing left to resolve is what to do with our sims. We are not particularly interested in any individual simulation in any individual time period. Rather, we can get a sense of the central effect of the shockvar on $y$ by doing some meaningful analysis across the simulations within any time period. Accordingly, in foo\$simulation, dynardl stores the desired summary quantity of interest (either qoi $=$ "mean" or qoi = "median") of $y$ in each time period. It also stores the lower and upper percentiles for the $75 \%, 90 \%$ and $95 \%$ intervals. Users can add additional intervals with sig. Additionally, users can specify whether they want predicted values (the average across the simulations within a time period) or expected values (where each individual simulation essentially averages out fundamental error). This is through the option expectedval = FALSE or TRUE, respectively; we highly recommend the former.

Moving back to our substantive example, now that we have our model and found the relationship to be cointegrating, we move onto interpreting the results through dynamic simulations. Again, although analytic calculations of short- and long-run effects are possible (c.f., De Boef and Keele, 2008), 
with a multitude of lags and lagged first differences, the ability to interpret the effect on $y$, given a change in a regressor, can become even more difficult. One of the easiest ways of getting a sense of the effect of the shockvar on $y$ is through plotting the simulation results (Tomz et al., 2003; Breunig and Busemeyer, 2012; Williams and Whitten, 2012; Philips et al., 2015, 2016; Gandrud et al., 2015; Blackwell and Glynn, 2018; Choirat et al., 2018). To this end, we offer two more functions: area. simulation. plot and spike.simulation.plot. The only difference is whether an area plot or a spike plot is desired (both are illustrated below). The arguments for both functions are:

- $x$, a dynardl model object with a simulation to plot.

- response, whether the the simulated response of the dependent variable should be plotted in absolute levels of the response, or in changes from the mean value of the dependent variable (response = "mean. changes"). The default is response = "levels".

- bw, whether the plot should be produced in black and white (for publications) or color. The default is bw = FALSE (a color plot).

To plot these simulations, all the researcher needs to do is imagine the counterfactual he or she wishes to investigate. For instance, what is the effect of a 7-percentage-point increase in Income Top 10 on Concern? To examine statistical and substantive significance of this counterfactual, we estimate the following model below and plot it. Note that users may want to first set a seed in order to ensure that the plots are reproducible, since the simulations are stochastic. The resulting plot is shown in Figure 1.
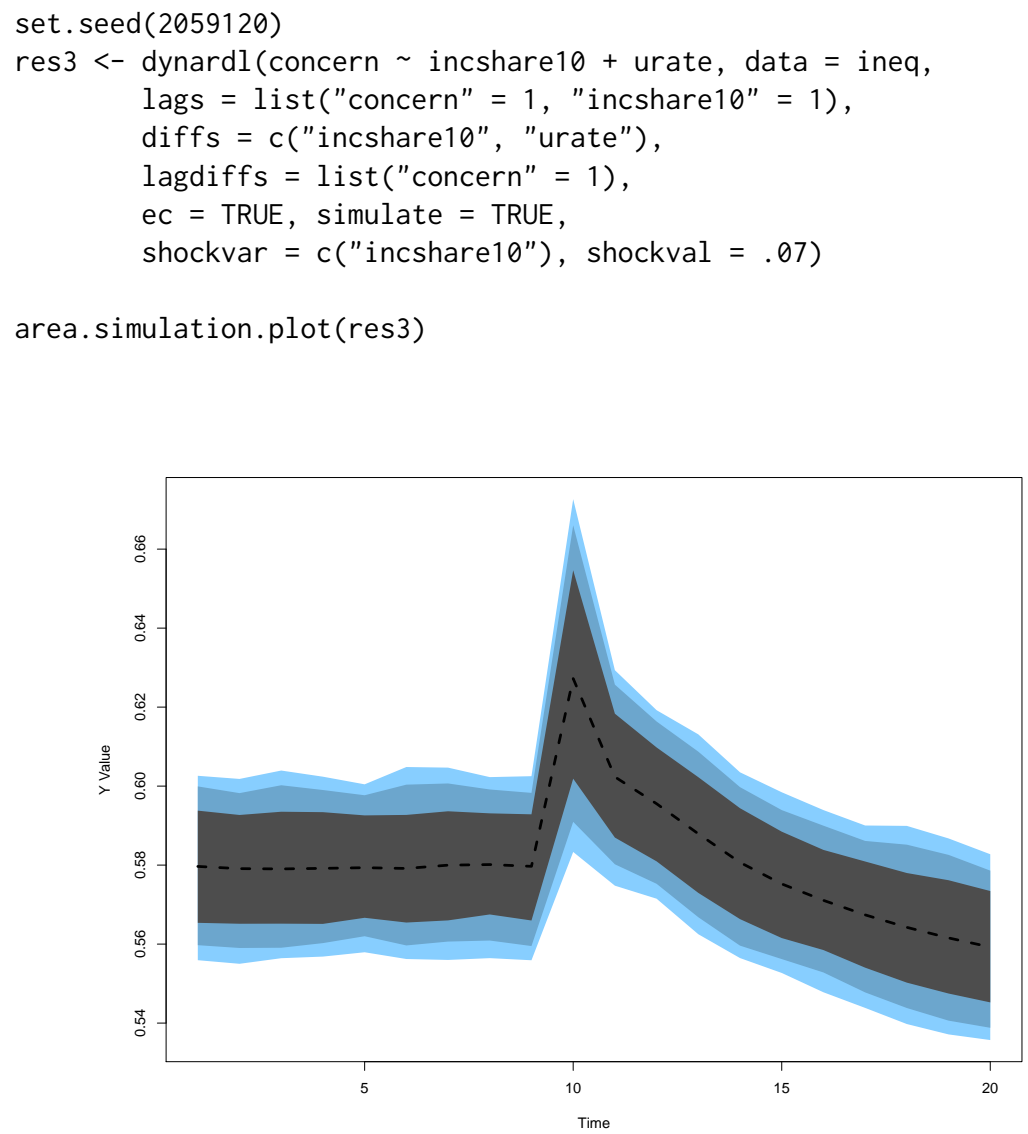

Figure 1: Area plot produced using area.simulation.plot()

The black dotted line shows the predicted value, while the colored areas, from darkest to lightest, show the 75,90, and 95 percentiles of the predictions from the simulations, something akin to a credible interval or confidence interval. The shock to Income Top 10 occurs by default at $t=10$, though users can change this using the time option. If instead we desire a spikeplot, we could type:

spike.simulation.plot(res3)

The resulting plot is shown in Figure 2.

Figures 1 and 2 both illustrate that the immediate effect of a 7-percentage-point increase in Income Top 10 is to increase Concern by about 4 percentage points. Over time, this effect decays, eventually 


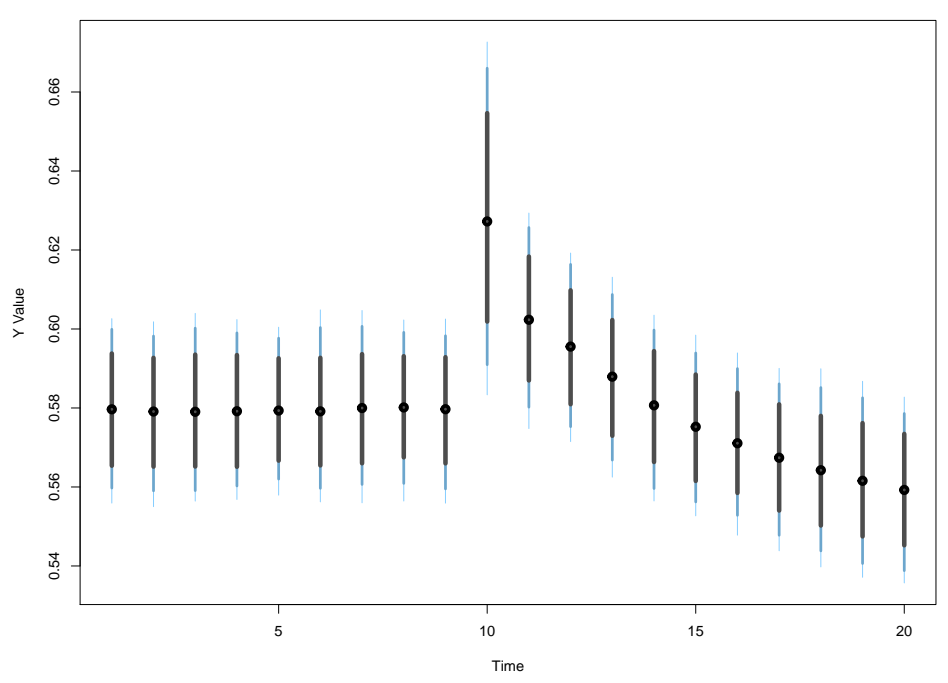

Figure 2: Spike plot produced using spike.simulation. plot()

moving Concern to a new value of 0.56 from its pre-shock mean of 0.58 . For clarity: these effects are produced by estimating the model formula given by the user, taking the estimated coefficients from the model, drawing a number of simulated coefficients from a multivariate normal distribution with mean and variance given by the estimated coefficients and variance-covariance from the model, and using them to predict values of the dependent variable (and incorporating fundamental error by drawing stochastic terms from $\hat{\sigma}^{2}$ ). It then tracks the response in these predicted values to simulated shifts in the independent variables. We might also note that the dependent variable could still be responding: users could increase the range of the simulation time periods to ensure that the dependent variable has enough time to respond.

Users may have noticed fluctuations in the confidence intervals shown in Figures 1 and 2. This is due to the stochastic sampling technique used to create these simulations. When using dynardl, users have the option of increasing the number of simulations performed using the sims option. This should have the effect of smoothing out period-to-period fluctuations in the confidence intervals, at the cost of increased computing time.

\section{Additional tools for dynamic analysis with dynamac}

dynardl has a number of additional features users may find useful. First, not only is it suitable for error-correction models; dynardl can model a variety of stationary ARDL processes. To see this, we show a simple example using data from Durr et al. (2000), who examine how ideological movements in the United States affect aggregate public support for the Supreme Court. Our model is:

$$
\begin{aligned}
\text { Supreme Court Support }_{t}= & \alpha+\phi_{1} \text { Supreme Court Support }_{t-1}+\beta_{1} \text { Ideological Divergence }_{t}+ \\
& \beta_{2} \text { Congressional Approval }_{t}+\epsilon_{t}
\end{aligned}
$$

where support for the US Supreme Court (1973-1993) (dcalc) is a function of a constant, the lag of Supreme Court Support, the ideological divergence between the Supreme Court and the public (Ideological Divergence, iddiv), and the level of Congressional Approval (congapp). ${ }^{22}$ To estimate this model using dynardl, we type:

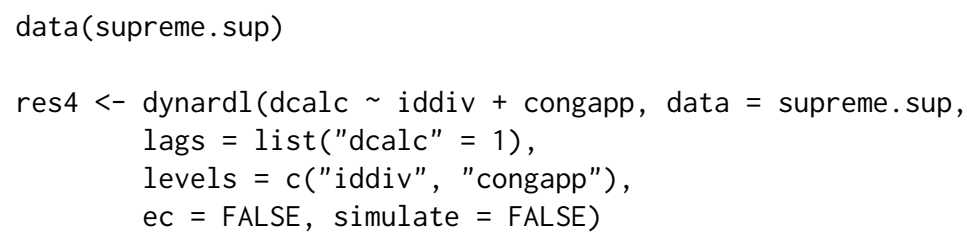

\footnotetext{
${ }^{22}$ As stressed in previous sections, stationarity testing is recommended on all dependent and independent variables before determining whether a stationary or error-correcting ARDL model should be estimated. This is a stylized example only meant to demonstrate additional capabilities of dynamac.
} 
[1] "Dependent variable to be run in levels."

Anytime we specify levels, any variables appearing in the list will be included contemporaneously (i.e., appear at time $t$ without any lags or differences) in the model. As with the error-correction specification, we can obtain regression results by typing:

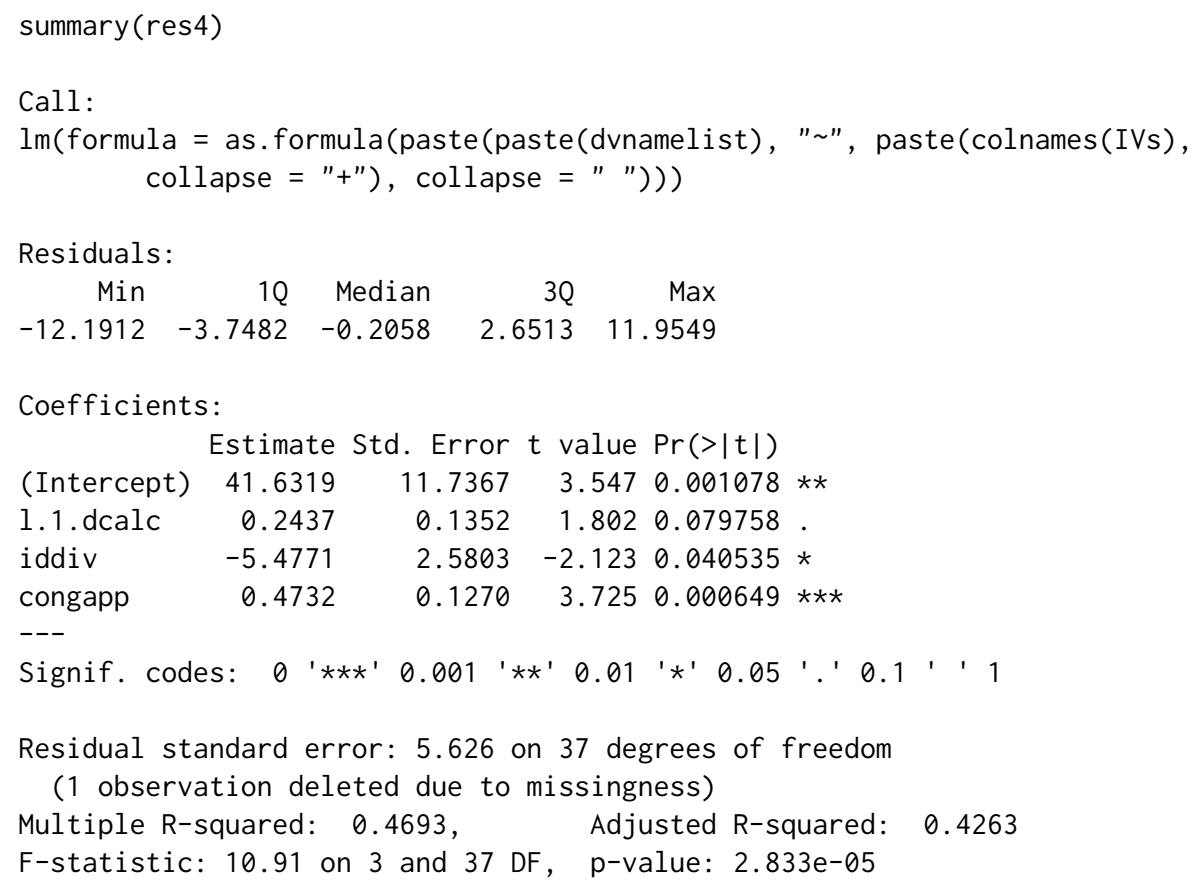

As the results show, the lag of Supreme Court Support is only weakly related to Supreme Court Support. Moreover, as Ideological Divergence grows, Supreme Court Support decreases. In contrast, as Congressional Approval increases, Supreme Court Support also increases. We can also bring a substantive interpretation to these effects by again using stochastic simulations. We can investigate the counterfactual of a 15-percentage-point decrease in Congressional Approval on Supreme Court Support. Moreover, we demonstrate the difference between the number of simulations used to generate predictions in Figure 3.

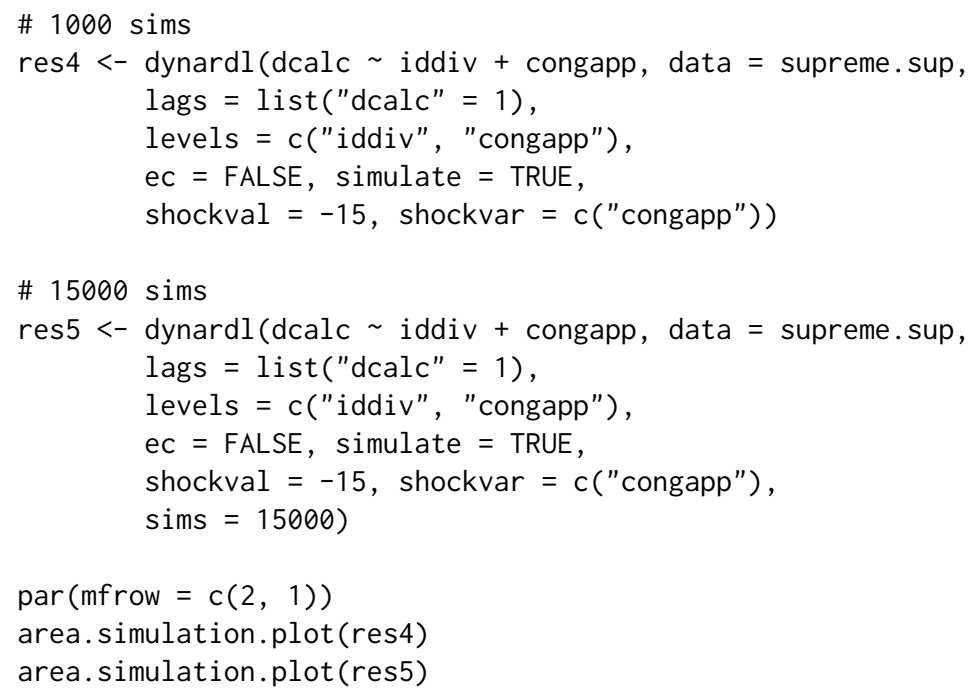

The effect of the 15-percentage-point decrease in Congressional Approval is about a 10-point decrease in Supreme Court Support. To uncover this effect, the upper plot uses 1000 simulations, while the bottom uses 15000 and results in a much smoother measure of uncertainty in predictions across the simulated timeframe, with only a slight increase in estimation time. ${ }^{23}$ Of course, it is important to note that simulations do not lower uncertainty (simulating more values does not decrease the underlying variance). More simulations just improve and smooth our estimates within each time period.

\footnotetext{
${ }^{23}$ For comparison, in this model, 1000 simulations took 3.98 seconds, while 15,000 took 4.12 seconds.
} 

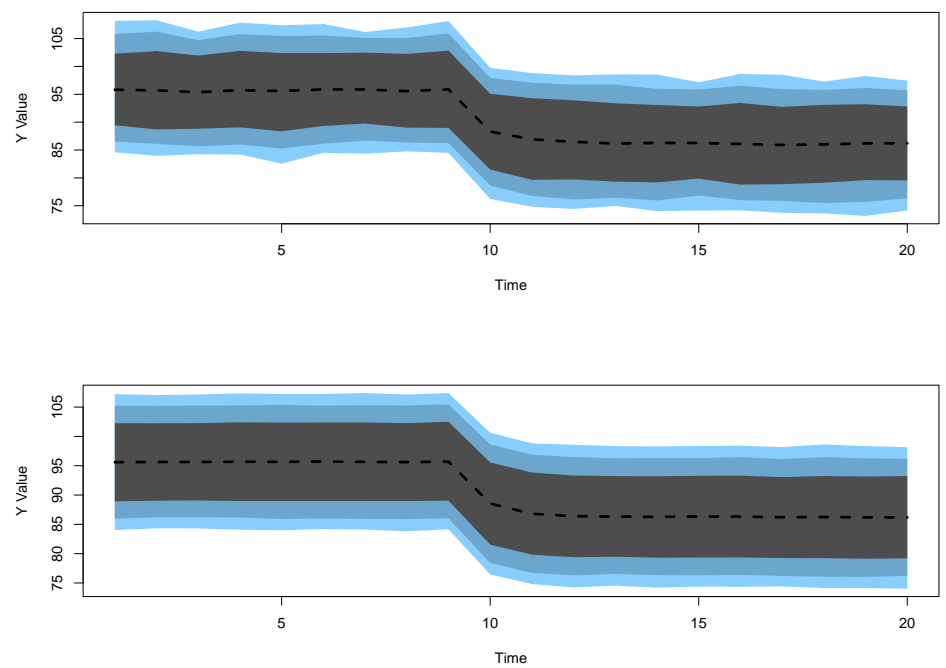

Figure 3: Effect of a 15-percentage-point decrease in Congressional Approval; 1000 simulations (default) (top) and 15000 (bottom)

While the default range for simulations is 20 time periods, with a shock occurring at time $t=10$-as shown in Figure 3 for instance-users can change these using the time and range options. In addition, dynardl offers the ability to set variables at particular values other than their means throughout the simulation through the option forceset. ${ }^{24}$ This would be ideal when the mean value is not particularly intuitive or of substantive interest, such as when dealing with a dichotomous variable. Instead, users can specify particular values using the option forceset. As an example of this, we re-estimate the model from above, but extend the total simulation range to $t=50$, the shock time to $t=20$, and set both Congressional Approval and Ideological Divergence to their 75th percentiles instead of their means:

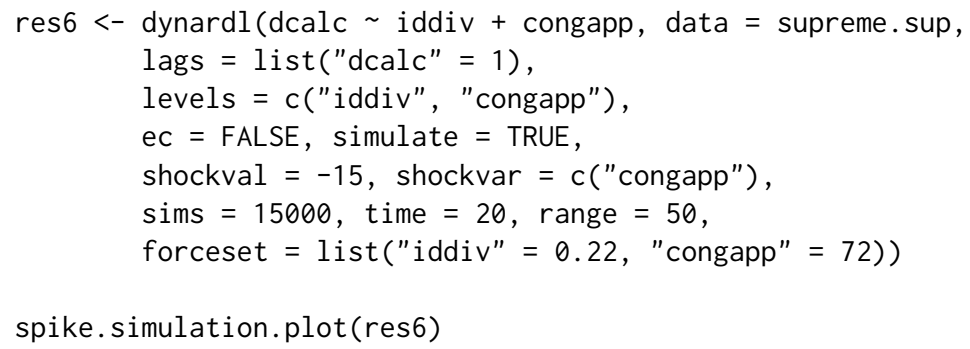

The results of a 15-percentage-point drop in Congressional Approval on Supreme Court Support are shown in Figure 4. It is clear that there is a relatively quick negative effect on Supreme Court Support in response to a drop in Congressional Approval, and Supreme Court Support remains at around 88 for the rest of the time periods.

dynamac also offers a few ancillary functions to help assist in dynamic modeling using autoregressive distributed lag models and dynardl in particular. These include three basic time-series operators to lag, difference, and lag-difference variables. Users are free to utilize these functions outside of estimating the models.

For lagging variables, we use $1 \operatorname{shift}(x, 1)$, where $x$ is the variable to be lagged and 1 is the number of periods to be lagged. If a user wanted a second lag (that is $X_{t-2}$, he or she would use lshift $(X, 2)$ :

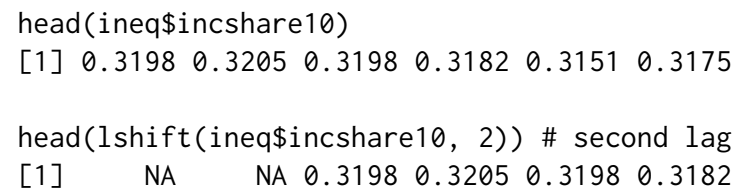

For differencing variables, we use $\operatorname{dshift}(x)$, where $x$ is the variable to be first-differenced:

\footnotetext{
${ }^{24}$ Recall that, by default, variables in levels are set to their means throughout the simulation (unless shocked), while variables in differences are set to zero.
} 


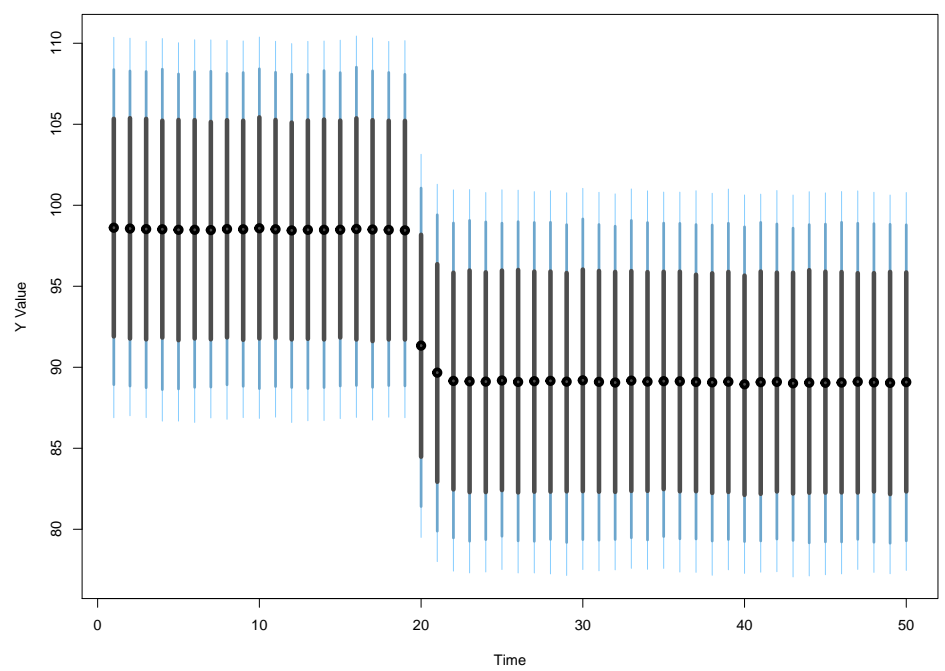

Figure 4: Extending the simulation range and using forceset

head(dshift (ineq $\$$ incshare10))

[1] NA $\quad 0.0007 \quad-0.0007 \quad-0.0016 \quad-0.0031 \quad 0.0024$

For lag-differencing variables, we use $1 \mathrm{dshift}(\mathrm{x}, 1)$, where $\mathrm{x}$ is the variable to be lag-differenced and $l$ is the number of periods for the difference to be lagged. If a user wanted for the difference of $X$ from two time periods ago $\left(\Delta X_{t-2}\right)$ to be calculated, he or she would use ldshift $(X, 2)$ :

head(1dshift (ineq $\$$ incshare10, 2))

[1] NA NA $\quad$ NA $\quad 0.0007 \quad-0.0007 \quad-0.0016$

\section{Additional example: the GDP-energy nexus}

As a final example, we model the relationship between a country's energy consumption and its economic output. There is a substantial body of literature that focuses on both the short-and long-run effects between energy and GDP — as well as the directionality of the relationship — making it a prime candidate for time series analysis (Ozturk, 2010; Tugcu et al., 2012). In fact, a number of articles utilize the bounds testing approach discussed above (e.g., Odhiambo, 2009; Fuinhas and Marques, 2012). In the analysis below, we focus on two key variables: the natural log of gross domestic product (in constant 2010 US dollars) and the log of energy consumption (in million tons of oil equivalent). These data are for the French economy, measured annually from 1965 to $2017 .{ }^{25}$ For this example, we assume that energy consumption, Inenergy, drives GDP, InGDP_cons2010USD, not the other way around.

As Figure 5 suggests, both series appear non-stationary, with probably a trend as well. Unit-root tests (not shown) confirm that both series contain a unit root. Therefore, we proceed to estimate an ARDL model in error-correction form with a deterministic trend, test for cointegration, and interpret the results.

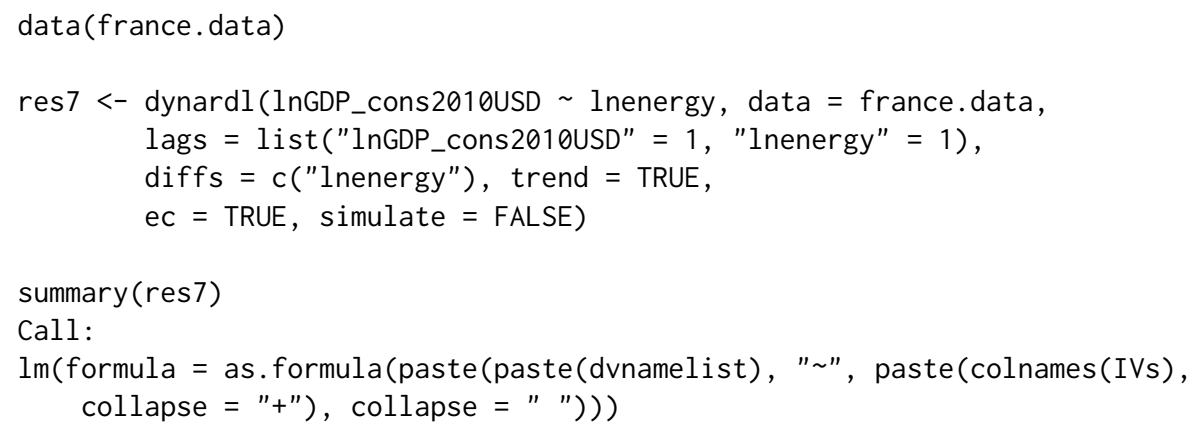

${ }^{25} \mathrm{GDP}$ data are from the World Bank World Development Indicators. Data on energy consumption are from the BP Statistical Review of World Energy (June 2018), available at: https://www.bp.com/en/global/corporate/energy-economics/statistical-review-of-world-energy.html. 


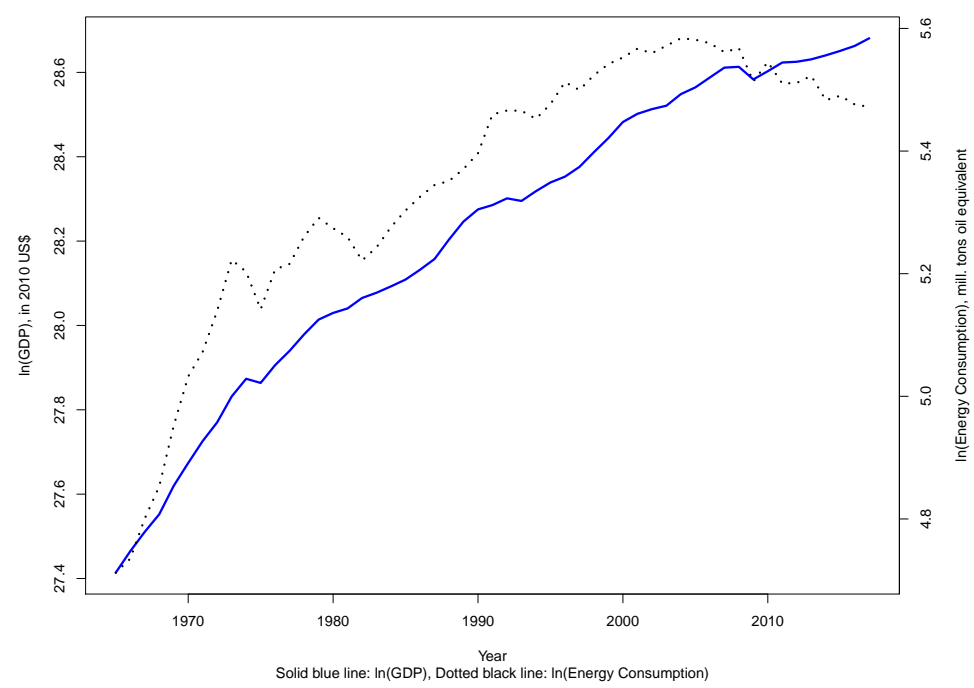

Figure 5: GDP and energy consumption in France, 1965-2017

Residuals:

$\begin{array}{rrrrr}\text { Min } & 1 Q & \text { Median } & 3 Q & \text { Max } \\ -0.0262561 & -0.0056128 & 0.0000717 & 0.0053919 & 0.0246083\end{array}$

Coefficients:

\begin{tabular}{|c|c|c|c|}
\hline & Estimate Std. Error & value $\operatorname{Pr}$ & \\
\hline (Intercept) & $6.995130 \quad 1.743518$ & 4.0120 .0 & $\star * *$ \\
\hline .1.lnGDP_cons2010USD & -0.283335 & -3.9600 .000253 & $\star \star \star$ \\
\hline 1. lnenergy & 0.257645 & $4.632 \quad 2.8$ & $\star * *$ \\
\hline & 796 & 3.4980 .0 & ** \\
\hline trendvar & 0.001063 & 3.5980 .000769 & $\star * *$ \\
\hline ignif. codes: 0 '*** & *' 0.001 '**' 0.01 '*' & 0.1 & 1 \\
\hline \multicolumn{4}{|c|}{$\begin{array}{l}\text { Residual standard error: } 0.01112 \text { on } 47 \text { degrees of freedom } \\
\text { ( } 1 \text { observation deleted due to missingness) }\end{array}$} \\
\hline $\begin{array}{l}\text { ultiple R-squared: } 0 \\
\text {-statistic: } 23.72 \text { on }\end{array}$ & $0.6688, \quad$ Adjuste & d R-squared: $\quad 0.6$ & \\
\hline
\end{tabular}

As is clear from the regression results, there appears to be a fairly slow rate of re-equilibration when the two series are out of their long-run equilibrium relationship, as shown by the coefficient on the lagged dependent variable. Moreover, both the first-difference and lag of the log of energy consumption, as well as the trend variable, are statistically significant. Before proceeding to test for cointegration, we ensure the residuals are white-noise using dynardl . auto. correlated:

dynardl. auto.correlated(res7)

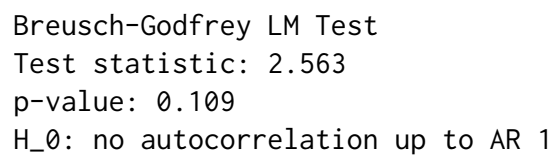

Log-likelihood: 162.789 


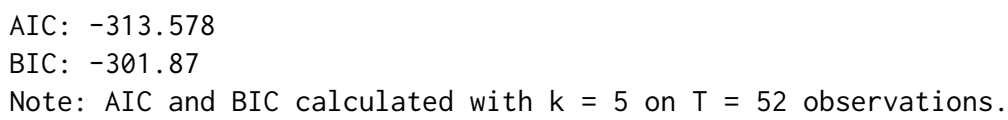

The Breusch-Godfrey test suggests there is no residual autocorrelation of order AR(1), and the residuals are approximately normally distributed. In addition, using the information criteria reported in dynardl. auto.correlated, we find that the model with a trend term estimated above is more consistent with the data than one without (these results are not reported here). Given that the model appears to be well-specified, we proceed to test for cointegration. Note that the program automatically selects critical values from "Case 5", an unrestricted intercept and trend:

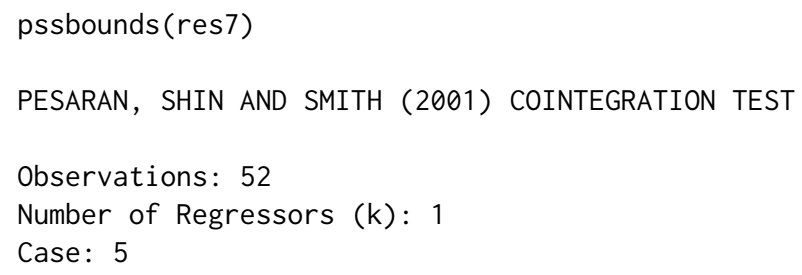

\begin{tabular}{|c|c|c|}
\hline - & F-test & \\
\hline \multicolumn{3}{|c|}{$<------I(0)-$} \\
\hline $10 \%$ critical value & 5.8 & 6.515 \\
\hline $5 \%$ critical value & 6.93 & 7.785 \\
\hline $1 \%$ critical value & 9.8 & 10.675 \\
\hline
\end{tabular}

$\begin{array}{lll} & \text { t-test } & - \\ \text { 10\% critical value } & -3.13 & -3.4 \\ 5 \% \text { critical value } & -3.41 & -3.69 \\ 1 \% \text { critical value } & -3.96 & -4.26\end{array}$

$t$ statistic $=-3.96$

t-statistic note: Small-sample critical values not provided for Case $V$. Asymptotic critical values used.

Since the F-statistic (i.e., the test that all variables appearing in lagged levels are equal to zero) is larger than the I(1) critical value in the table at the 5\% level, we conclude that cointegration between energy consumption and economic output exists. In addition, the one-sided t-test of the coefficient on the lagged dependent variable also supports the conclusion of cointegration. Given our model results, and finding evidence of cointegration, we turn to a substantive interpretation of our findings: what would be the effect of a one standard deviation decrease in energy consumption on GDP?

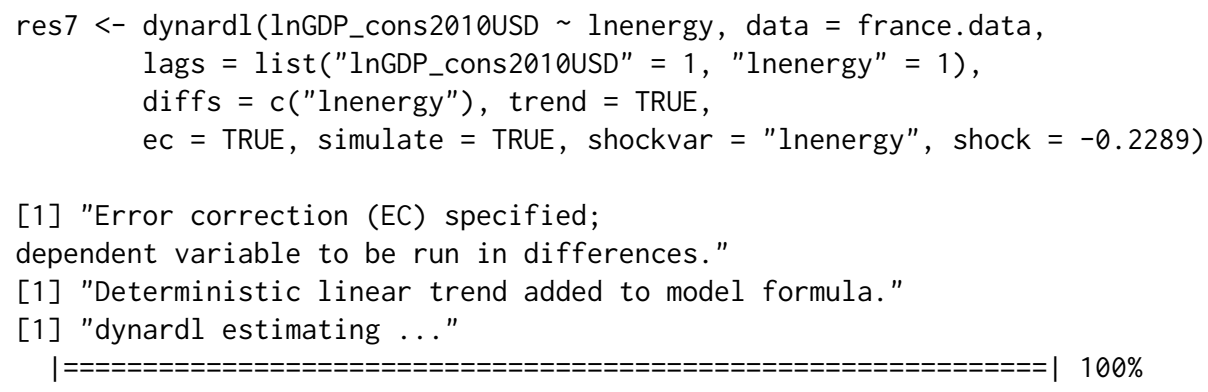


As shown by the spikeplot in Figure 6, the pre-shock (i.e., any prediction before $t=10$ ) values are consistently increasing over time; this is due to the trend term. At $t=10$, the one standard deviation decrease in energy consumption occurs. This effect does not result in a statistically significant decrease in the contemporaneous period, but continues to lower GDP until two periods after the shock occurs. Moreover, it is not until 10 years after this hypothetical shock that GDP returns to its pre-shock level.

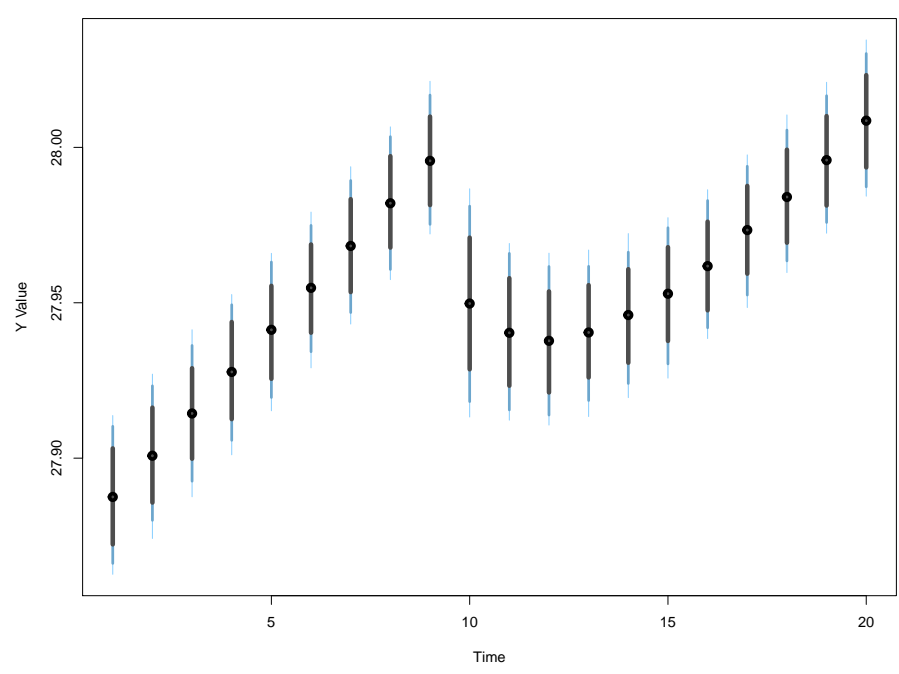

Figure 6: The effect of a one standard deviation decrease in energy consumption on economic growth

\section{Conclusion}

In this paper we have introduced dynamac, a suite of functions designed to assist applied time series analysts. This centers around dynardl, a multipurpose function to estimate autoregressive distributed lag models. This flexible program models both stationary ARDL relationships as well as cointegrating ones, and it allows users to easily change model specifications (e.g., lags, differences, and lag-differences). We also include two post-estimation diagnostic commands to check for white-noise residuals and cointegration. Last, through several applied examples we have shown the advantages of dynamic simulation for interpreting the substantive significance of the results of single-equation time series models, something users can easily do using dynamac.

There are a number of interesting potential future research areas. Most useful would be extending ARDL modeling to the panel context. While other packages are designed to handle multiple panels (c.f., Gandrud et al., 2016), the ability to incorporate models that account for unit heterogeneity, such as random or fixed intercepts, would prove useful to users. In addition, adding the ability to estimate alternative models in the dynamic panel data context, such as those that account for causal feedback and time-varying covariates (Blackwell and Glynn, 2018), or generalized method of moments (GMM) estimators, would also assist practitioners.

\section{Bibliography}

N. Beck and J. N. Katz. Modeling dynamics in time-series-cross-section political economy data. Annual Review of Political Science, 14:331-352, 2011. URL https://doi.org/10.1146/annurev-polisci071510-103222. [p469]

M. Blackwell and A. N. Glynn. How to make causal inferences with time-series cross-sectional data under selection on observables. American Political Science Review, 112(4):1067-1082, 2018. URL https://doi.org/10.1017/S0003055418000357. [p469, 479, 486]

C. Breunig and M. R. Busemeyer. Fiscal austerity and the trade-off between public investment and social spending. Journal of European Public Policy, 19(6):921-938, 2012. URL https://doi . org/10. 1080/13501763.2011.614158. [p471,479]

C. Choirat, C. Gandrud, J. Honaker, K. Imai, G. King, and O. Lau. Zelig: Everyone's Statistical Software, 2018. URL https://CRAN. R-project.org/package=Zelig. R package version 5.1.6. [p470, 471, 479] 
H. D. Clarke, K. Ho, and M. C. Stewart. Major's lesser (not minor) effects: Prime ministerial approval and governing party support in Britain since 1979. Electoral Studies, 19(2):255-273, 2000. URL https://doi.org/10.1016/S0261-3794(99)00051-7. [p469]

S. De Boef and L. Keele. Taking time seriously. American Journal of Political Science, 52(1):184-200, 2008. URL https://doi.org/10.1111/j.1540-5907.2007.00307.x. [p469,470,478]

R. H. Durr, A. D. Martin, and C. Wolbrecht. Ideological divergence and public support for the Supreme Court. American Journal of Political Science, pages 768-776, 2000. URL https://doi .org/10.2307/ 2669280. [p480]

R. F. Engle and C. W. Granger. Co-integration and error correction: Representation, estimation, and testing. Econometrica, 55(2):251-276, 1987. URL https://doi .org/10.2307/1913236. [p471, 472]

J. A. Fuinhas and A. C. Marques. Energy consumption and economic growth nexus in Portugal, Italy, Greece, Spain and Turkey: An ARDL bounds test approach (1965-2009). Energy Economics, 34(2): 511-517, 2012. URL https://doi.org/10.1016/j.eneco.2011.10.003. [p483]

C. Gandrud, L. K. Williams, and G. D. Whitten. Dynsim: Dynamic Simulations of Autoregressive Relationships, 2015. URL https://CRAN. R-project.org/package=dynsim. R package version 1.2.1. [p470, 471, 479]

C. Gandrud, L. K. Williams, and G. D. Whitten. Visualize dynamic simulations of autoregressive relationships in R. The Political Methodologist, 23(2):6-10, 2016. [p470, 486]

T. Grant and M. J. Lebo. Error correction methods with political time series. Political Analysis, 24(1): 3-30, 2016. URL https://doi.org/10.1093/pan/mpv027. [p475]

D. Jacobs and R. E. Helms. Toward a political model of incarceration: A time-series examination of multiple explanations for prison admission rates. American Journal of Sociology, 102(2):323-357, 1996. URL https://doi .org/10.1086/230949. [p469]

S. Johansen. Estimation and hypothesis testing of cointegration vectors in Gaussian vector autoregressive models. Econometrica: Journal of the Econometric Society, 59(6):1551-1580, 1991. URL https://doi.org/10.2307/2938278. [p471]

S. Johansen. Likelihood-Based Inference in Cointegrated Vector Autoregressive Models. Oxford University Press, 1995. URL https://doi.org/10.1093/0198774508.001.0001. [p471,472]

S. Jordan and A. Q. Philips. Dynamac: Dynamic Simulation and Testing for Single-Equation ARDL Models, 2018. URL https://CRAN. R-project.org/package=dynamac. R package version 0.1.6. [p469]

L. Keele and N. J. Kelly. Dynamic models for dynamic theories: The ins and outs of lagged dependent variables. Political Analysis, 14(2):186-205, 2006. URL https: //doi .org/10.1093/pan/mpj006. [p473, 474]

K. Mertens and J. L. Montiel Olea. Marginal tax rates and income: New time series evidence. The Quarterly Journal of Economics, 133(4):1803-1884, 2018. URL https://doi .org/10.1093/qje/qjy008. [p469]

G. E. Mizon. A simple message for autocorrelation correctors: Don't. Journal of Econometrics, 69(1): 267-288, 1995. URL https://doi .org/10.1016/0304-4076(94)01671-L. [p474]

P. K. Narayan. The saving and investment nexus for China: Evidence from cointegration tests. Applied Economics, 37(17):1979-1990, 2005. URL https://doi .org/10. 1080/00036840500278103. [p476, 477]

N. M. Odhiambo. Energy consumption and economic growth nexus in Tanzania: An ARDL bounds testing approach. Energy Policy, 37(2):617-622, 2009. URL https://doi.org/10.1016/j. enpol. 2008.09.077. [p483]

I. Ozturk. A literature survey on energy-growth nexus. Energy Policy, 38(1):340-349, 2010. URL https://doi.org/10.1016/j.enpol.2009.09.024. [p483]

M. H. Pesaran, Y. Shin, and R. J. Smith. Bounds testing approaches to the analysis of level relationships. Journal of Applied Econometrics, 16(3):289-326, 2001. URL https: //doi .org/10.1002/ jae.616. [p469, $470,471,473,475,476,477]$

B. Pfaff, E. Zivot, and M. Stigler. Urca: Unit Root and Cointegration Tests for Time Series Data, 2016. URL https: //CRAN. R-project.org/package=urca. R package version 1.3-0. [p471] 
A. Q. Philips. Have your cake and eat it too? Cointegration and dynamic inference from autoregressive distributed lag models. American Journal of Political Science, 62(1):230-244, 2018. URL https: //doi.org/10.1111/ajps. 12318. [p471, 472,474,475, 476, 477]

A. Q. Philips, A. Rutherford, and G. D. Whitten. The dynamic battle for pieces of pie-modeling party support in multi-party nations. Electoral Studies, 39:264-274, 2015. URL https: //doi . org/10.1016/ j.electstud.2015.03.019. [p471,479]

A. Q. Philips, A. Rutherford, and G. D. Whitten. Dynamic pie: A strategy for modeling trade-offs in compositional variables over time. American Journal of Political Science, 60(1):268-283, 2016. URL https://doi.org/10.1111/ajps.12204. [p471, 479]

C. Rainey. Transformation-induced bias: Unbiased coefficients do not imply unbiased quantities of interest. Political Analysis, 25(3):402-409, 2017. URL https://doi .org/10.1017/pan.2017.11. [p478]

B. Ripley. MASS: Support Functions and Datasets for Venables and Ripley's MASS, 2018. URL https: //CRAN.R-project.org/package=MASS. R package version 7.3-49. [p478]

M. Tomz, J. Wittenberg, and G. King. Clarify: Software for interpreting and presenting statistical results. Journal of Statistical Software, 8(1):1-30, 2003. URL https://doi .org/10.18637/ jss . v008. i01. [p471, 479]

C. T. Tugcu, I. Ozturk, and A. Aslan. Renewable and non-renewable energy consumption and economic growth relationship revisited: Evidence from G7 countries. Energy Economics, 34(6):1942-1950, 2012. URL https://doi.org/10.1016/j.eneco.2012.08.021. [p483]

L. K. Williams and G. D. Whitten. But wait, there's more! Maximizing substantive inferences from TSCS models. The Journal of Politics, 74(03):685-693, 2012. URL https: //doi . org/10.1017/ s0022381612000473. [p471,479]

C. Wlezien. The public as thermostat: Dynamics of preferences for spending. American Journal of Political Science, pages 981-1000, 1995. URL https://doi.org/10.2307/2111666. [p469]

G. Wright. The political implications of American concerns about economic inequality. Political Behavior, pages 1-23, 2017. URL https://doi .org/10.1007/s11109-017-9399-3. [p471]

\author{
Soren Jordan \\ Department of Political Science \\ Auburn University \\ United States \\ sorenjordanpols@gmail.com \\ Andrew Q. Philips \\ Department of Political Science \\ University of Colorado Boulder \\ United States \\ andrew.philips@colorado.edu
}

